\title{
Expression of pair rule gene orthologs in the blastoderm of a myriapod: evidence for pair rule-like mechanisms?
}

\author{
Ralf Janssen ${ }^{*}$, Wim G M Damen ${ }^{2}$ and Graham E Budd ${ }^{1}$
}

\begin{abstract}
Background: A hallmark of Drosophila segmentation is the stepwise subdivision of the body into smaller and smaller units, and finally into the segments. This is achieved by the function of the well-understood segmentation gene cascade. The first molecular sign of a segmented body appears with the action of the pair rule genes, which are expressed as transversal stripes in alternating segments. Drosophila development, however, is derived, and in most other arthropods only the anterior body is patterned (almost) simultaneously from a pre-existing field of cells; posterior segments are added sequentially from a posterior segment addition zone. A long-standing question is to what extent segmentation mechanisms known from Drosophila may be conserved in short-germ arthropods. Despite the derived developmental modes, it appears more likely that conserved mechanisms can be found in anterior patterning.

Results: Expression analysis of pair rule gene orthologs in the blastoderm of the pill millipede Glomeris marginata (Myriapoda: Diplopoda) suggests that these genes are generally involved in segmenting the anterior embryo. We find that the Glomeris pairberry-1 (pby-1) gene is expressed in a pair rule pattern that is also found in insects and a chelicerate, the mite Tetraynchus urticae. Other Glomeris pair rule gene orthologs are expressed in double segment wide domains in the blastoderm, which at subsequent stages split into two stripes in adjacent segments.

Conclusions: The expression patterns of the millipede pair rule gene orthologs resemble pair rule patterning in Drosophila and other insects, and thus represent evidence for the presence of an ancestral pair rule-like mechanism in myriapods. We discuss the possibilities that blastoderm patterning may be conserved in long-germ and short-germ arthropods, and that a posterior double segmental mechanism may be present in short-germ arthropods.
\end{abstract}

Keywords: Evolution, Pair rule patterning, Segmentation, Paired, Even-skipped, Runt, Hairy, Odd-paired, Sloppy-paired, Odd-skipped

\section{Background}

In Drosophila, a hierarchic segmentation gene cascade acts to stepwise pattern the early embryo into single segments (reviewed in [1-3]). Maternally provided factors such as bicoid and hunchback, rest at the top of this hierarchy, which allows these genes to regulate zygotically expressed gap genes (GGs) ([4], reviewed in [5]). The GGs, that are expressed in broad overlapping domains along the anterior-posterior axis of the embryo,

\footnotetext{
* Correspondence: ralf.janssen@geo.uu.se

'Department of Earth Sciences, Uppsala University, Villavägen 16, 75236 Uppsala, Sweden

Full list of author information is available at the end of the article
}

regulate the pair rule genes (PRGs) in transversal stripes in alternating segment primordia [6]. During a subsequent phase of segment formation, the PRGs are often expressed in a single segmental periodicity and, at this point, act as segment-polarity genes (SPGs) (e.g. [7,8]). In a combinatorial mode the PRGs regulate the expression of the SPGs, which maintain the parasegment boundaries and define the segments' polarity.

This mode of segment formation is called long-germ developmental mode because all segments are patterned from a pre-existing field of cells, the blastoderm (e.g. [9]). Drosophila development, however, is derived, and is, at best, comparable to some groups of higher insects. 
Only the most anterior segments form from the blastoderm in the majority of arthropods, while the posterior segments are added in a single or double segment period from a posterior segment addition zone (SAZ) [10]. This ancestral mode of development and segment formation is called short-germ developmental mode.

Recent studies have shown that the mechanisms and gene interactions acting at the bottom level of the Drosophila segmentation gene cascade, i.e. SPGs and Hox genes, appear to be highly conserved among arthropods (e.g. [11-15]) and onychophorans [16,17]. At the level of maternally provided effect genes and GGs, however, the segmentation gene hierarchy appears to be less conserved (e.g. [18]). The level at which the PRGs act is intermediate between that of the SPGs and Hox genes, and that of maternally provided effect genes and GGs (e.g. [2]). Examination of PRG expression and function in insects other than Drosophila revealed that this level of the segmentation gene cascade is, to some degree, conserved in insects (e.g. [19-21]). The expression profile of PRGs in most insects is, however, somewhat different from that in Drosophila. In non-Drosophilid long-germ insects, PRGs are often initially expressed in double-segment wide stripes that later split into a single segmental pattern (e.g. [22,23]). In short-germ insects a similar pattern is found in the anterior blastoderm, but during posterior segment addition PRGs are, like in non-insect arthropods, usually expressed in both dynamic patterns in the SAZ and in stripes in the newly formed segment(s) (e.g. [14,24-28]). It is therefore debatable whether they are involved in a pair rule-like mechanism (e.g. $[2,18,29])$. Data on early PRG expression or function in the blastoderm in non-insect arthropods are scant $[30,31]$ and for that reason, it is unclear whether a pair rule-like mechanism may be present in anterior patterning.

To shed light on this topic we examined the expression of most of the known Drosophila PRG orthologs in the blastoderm of the pill millipede Glomeris marginata (Myriapoda). The orthologs of two Drosophila PRG genes are not subject of this study: The fushi-tarazu gene acts as a classical PRG in Drosophila, but in basal hexapods and other arthropods, including Glomeris, it may have retained its ancestral role as Hox gene and does not act as a PRG [25,32-34]. The tenascin-major (ten-m) gene (aka odz) is a rather atypical PRG in Drosophila. It does not encode a transcription factor, like all other PRGs, and only has been student in Drosophila where it is only expressed in a pair rule pattern on protein level, but not on mRNA level. Therefore we decided not to include ten- $m$ in the present analysis. We find that all investigated PRG orthologs, except one, are expressed in transversal stripes that are typical for segmentation genes and which are in patterns that may be in accord with an underlying pair rule-like mechanism. The blastodermal expression of the PRGs is different from that in segments added from the SAZ in Glomeris [24]: they do not appear in a strict anterior to posterior order and are often initially expressed in double (or multiple) segment-wide domains.

\section{Methods}

Species husbandry, gene cloning, in situ hybridization, nuclei staining and documentation techniques

The handling of Glomeris marginata is described in [11]. After oviposition, embryos were allowed to develop at room temperature. Staging was done afterwards [11]. The developmental stage of all embryos was determined by using the dye, DAPI (4'-6-Diamidino-2-phenylindole).

Cloning and sequence analysis of the Glomeris pair rule gene orthologs has been described in [24].

Single whole mount in situ hybridization was performed as described in [35]. Double whole mount in situ hybridization was performed as described in [12].

Embryos were analyzed under a Leica dissection microscope equipped with either an Axiocam (Zeiss) or a Leica DC100 digital camera. Brightness, contrast, and color values were corrected in all images using the image processing software Adobe Photoshop CS2 (Version 9.0.1 for Apple Macintosh).

\section{Results}

Morphology of the early Glomeris embryo and technical limitations of in situ hybridization experiments

We previously reported on the expression profiles of PRG orthologs in the trunk of the pill millipede, Glomeris marginata [24]. Here we present the expression patterns of these genes in the anterior region of the developing embryo from the blastoderm stage (stage 0) to the formation of inter-segmental grooves at approximately stage 1 . Shortly after the formation of the blastoderm, a posterior zone of enhanced cell density appears (Figure 1A/A'); this domain is called the cumulus $[11,36]$. Soon after, a distinct area of enhanced cell density, the so-called regio germinalis, becomes visible anterior to the position of the cumulus and continues to grow into the anterior area of the developing embryo (Figure $\left.1 \mathrm{~B} / \mathrm{B}^{\prime}\right)$. All future anterior segments, including the first trunk segment (T1), are formed from the regio germinalis (Figure 1A-E). The anterior segments are patterned first but not completely simultaneously, as suggested by the expression of the SPG engrailed (en) (Figure $1 \mathrm{~A}^{\prime}-\mathrm{E}^{\prime}$ ) [11]. The posterior segments, including T2, form sequentially from a posterior SAZ. The term "SAZ" refers to the fact that this region, from which the posterior segments are added in a one by one period, does not represent an area of enhanced cell proliferation; we therefore want to avoid the somewhat misleading 


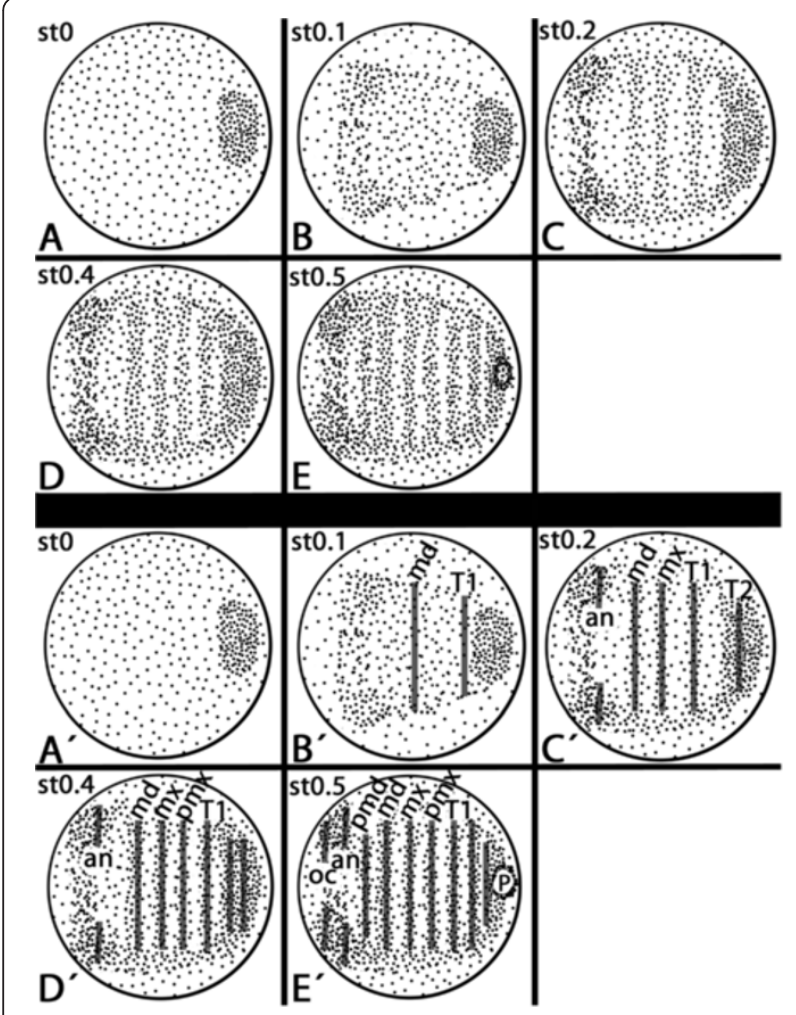

Figure 1 Schematic drawings representing the early development of Glomeris marginata from the blastoderm stage to formation and segmentation of the regio germinalis (A) Stage $\mathbf{0}$. A uniform blastoderm and a region of enhanced cell density at the posterior pole of the future embryo, the so-called cumulus, have formed. No expression of engrailed (en) (cf. to A'). (B) The regio germinalis forms anterior to the cumulus; the ocular field appears as an anterior region of enhanced cell density. en is expressed in the future mandibular and first trunk segment (T1) (cf. to $B^{\prime}$ ). (C) Segmentation of the regio germinalis begins. Transversal stripes of enhanced cell density corresponding to the later mandibular, maxillary and T1 segment appear. All anterior segments including $\mathrm{T} 1$ are formed from the regio germinalis; segments posterior to that are patterned from the segment addition zone (SAZ). At this stage the cumulus has transformed into the SAZ as indicated by the appearance of en expression corresponding to $\mathrm{T} 2$ in this region (cf. to $C^{\prime}$ ). en is now expressed in the antennal and the maxillary segment (cf. to $C^{\prime}$ ). (D) The postmaxillary segment primordium forms and expresses en (cf. to $D^{\prime}$ ); a second stripe of en-expression appears in the SAZ ( $\left.\mathrm{D}^{\prime}\right)$. (E) The premandibular segment primordium forms and expresses en ( $\left(f\right.$. to $E^{\prime}$ ). en appears de novo in the ocular region and posterior in the SAZ (cf. to E'). The proctodaeum forms. Abbreviations: an, antennal segment; md, mandibular segment; $m x$, maxillary segment; oc, ocular region; $\mathrm{P}$, proctodaeum; pmd, premandibular segment; pmx, postmaxillary segment; SAZ, segment addition zone; T1, first trunk segment.

terms growth- or proliferation-zone that are often used in this context (see also [37]).

Currently, it is not possible to perform mRNA detection studies (in situ hybridization) in embryos younger than stage 0 . At this stage the inner vitelline membrane forms in Glomeris. Attempts to fix embryos at earlier developmental stages (representing development from one to six days at room temperature) in the absence of a functional vitelline membrane, have failed.

\section{Expression of even-skipped (eve) in the regio germinalis}

In Drosophila the eve gene is under control of the upstream acting maternal effect genes and gap genes, and each of the seven transversal stripes of early eve-expression becomes specified separately by disjoined enhancer elements (e.g. [38-40]). Because of this direct control of eve by the upstream level segmentation genes it represents a primary PRG. One of its important functions during early development in Drosophila is to indirectly regulate the segment polarity gene engrailed by regulating its activators paired and fushi-tarazu and its repressors runt and sloppy paired [41]. The crucial function of eve among the PRGs is also conserved in other insects such as Tribolium [20,42] and Gryllus [28], but may be different in other insects (e.g. [43]).

Expression of Glomeris eve is detectable at the blastoderm stage as single stripes in the future premandibular and maxillary segment, a broad domain corresponding to the postmaxillary and first trunk segment (T1), and a second broad domain located in the posterior SAZ where the future T2 is patterned (Figure 2A). The most posterior region of the embryo is free from eve transcripts. These cells will later sink in and form the proctodaeum. The two posterior broad expression domains are in circles around the posterior pole of the embryo (Figure 2B). The same expression is described for eve at later developmental stages [24,44]. The postmaxillary +T1 domain begins to resolve into two distinct stripes (Figure 2C), and the posterior domain in the SAZ transforms into a distinct stripe (Figure 2C). The embryo shown in Figure $2 \mathrm{C}$ is double stained for eve and collier $(\mathrm{col})$, which serves as a spatial landmark. At this stage the col-stripe is located in the posterior part of the premandibular and the anterior part of the mandibular segment [45]. It now becomes clear that the intrasegmental position of the eve-stripe is anterior in the premandibular segment (Figure 2C). The small gap between the posterior edge of the col-stripe and the stripe of eve expression in the maxillary segment indicates that eve is located anteriorly in this segment. Double staining of eve and the segment polarity gene engrailed (en) supports this assumption and shows that eve is expressed posterior adjacent to en, and thus anterior in the segments (Additional file 1: Figure S1A). The intrasegmental position of eve in the regio germinalis is identical with that in the trunk segments (cf. [24]). The split of the postmaxillary+T1-domain progresses (Figure 2D), and at the subsequent stage 0.1 the split is complete (Figure 2E). A second stripe of eve appears in the SAZ 

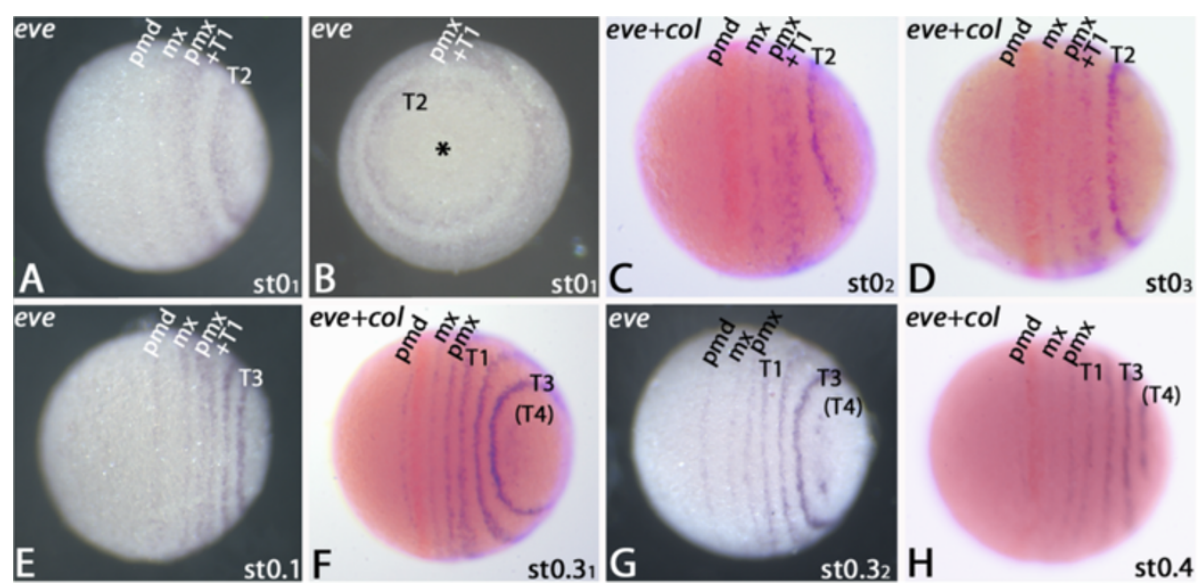

Figure 2 Expression of eve in the regio germinalis. All embryos are oriented with anterior to the left and represent ventral views, except panel (B), which represents a posterior view. Ventral (A) and posterior (B) view on an early blastoderm (stage $0_{1}$ ) embryo. Asterisk in (B) marks posterior pole of the embryo. (C) Later blastoderm stage embryo (stage $\mathrm{O}_{2}$ ) double-stained for eve (blue signal) and col (orange signal). (D) Late blastoderm stage embryo (stage 03) double-stained for eve and col. (E) Stage 0.1 embryo. (F) Stage 0.3 embryo double-stained for eve and col. Note that eve is not expressed in the mandibular segment. (G) Stage 0.32 embryo. (H) Stage 0.4 embryo. The full set of anterior eve-stripes has appeared. Abbreviations as in Figure 1.

(Figure 2E). At stage 0.3, expression corresponding to the later T4 segment appears in the SAZ. The premandibular stripe shortens, which is in accord with the changing morphology of this segment [11] (Figure 2F). The two dots that delimit the beginning of the dynamic cycles of eve expression in the SAZ first appear here (cf. [24]) (Figure 2G/H). Expression of eve in the premandibular and maxillary segments starts disappearing at stage 0.4 (Figure $2 \mathrm{H}$ ).

\section{Expression of runt (run) in the regio germinalis}

Like eve, also run acts as a primary PRG in Drosophila where one of its key functions is to regulate other PRGs as well as primary upstream acting gap genes (GGs) and maternal effect genes. In Drosophila run is thus an important component of the cross regulatory network of PRGs, GGs and maternal effect genes [46]. The important function of run in the pair rule regulatory network is conserved in short germ insects as well [20].

At the blastoderm stage, run is expressed as two broad domains corresponding to the later maxillary+postmaxillary segments and the $\mathrm{T} 1$ segment (Figure $3 \mathrm{~A} / \mathrm{B}$ ). Like eve, run is also expressed in rings that surround the posterior pole of the embryo. A third ring of run-expression corresponding to the future T2 segment appears in the SAZ (Figure 3C), and the anterior domain begins to split into two stripes. De novo expression appears in the posterior SAZ as a broad domain (Figure 3D). Splitting of the maxillary+postmaxillary domain proceeds (Figure 3E/F). A stripe of run representing T2 has split off from the SAZ (Figure $3 F$ ). At early stage 0.3 the maxillary+postmaxillary stripe has completely split (Figure 3G) and faint expression appears in the mandibular segment posterior and adjacent to the expression of $\mathrm{col}$ (Figure 3G). Expression of run appears in the ocular region (Figure $3 \mathrm{H}$ ). Coexpression of run $+\mathrm{col}$ reveals that run is expressed posterior and adjacent to col (Figure 3I/J) and is thus expressed in the anterior of the mandibular segment (cf. [24]). In the dorsal extraembryonic tissue the maxillary+postmaxillary stripe is, unlike in ventral tissue, not split (Figure 3I). In stage 0.4 embryos all segmental run-stripes are evenly spaced; DAPI counter-staining of the same embryo reveals the position of the stripes in the anterior of the now morphologically distinguishable segments (cf. Figure $3 \mathrm{~K}$ with $\mathrm{K}^{\prime}$ ).

\section{Expression of hairy-1 ( $h 1$ ) in the regio germinalis}

In Drosophila hairy acts as a primary PRG [47], but this function may only be partially conserved among insects $[19,20,48]$.

In the early blastoderm, $h 1$ is expressed in a broad domain covering the area of the future antennal to mandibular region (Figure 4A). At the posterior rim of this domain expression is enhanced. Faint expression is visible in the tissue that will form T1 (Figure 4A/B). Expression then disappears from the centre of the antennal to mandibular domain (Figure 4C). At the same time the level of expression at the anterior rim increases resulting in two distinct stripes: one in the antennal segment and one in the mandibular segment (Figure 4C). A stripe of $h 1$ appears within the SAZ (Figure 4C). De novo expression appears in the ocular region as a broad band while expression at the posterior rim of this domain is enhanced (Figure 4D). A very faint stripe appears in the maxillary segment (Figure 4D). Then additional stripes appear simultaneously in the SAZ and in the postmaxillary segment 


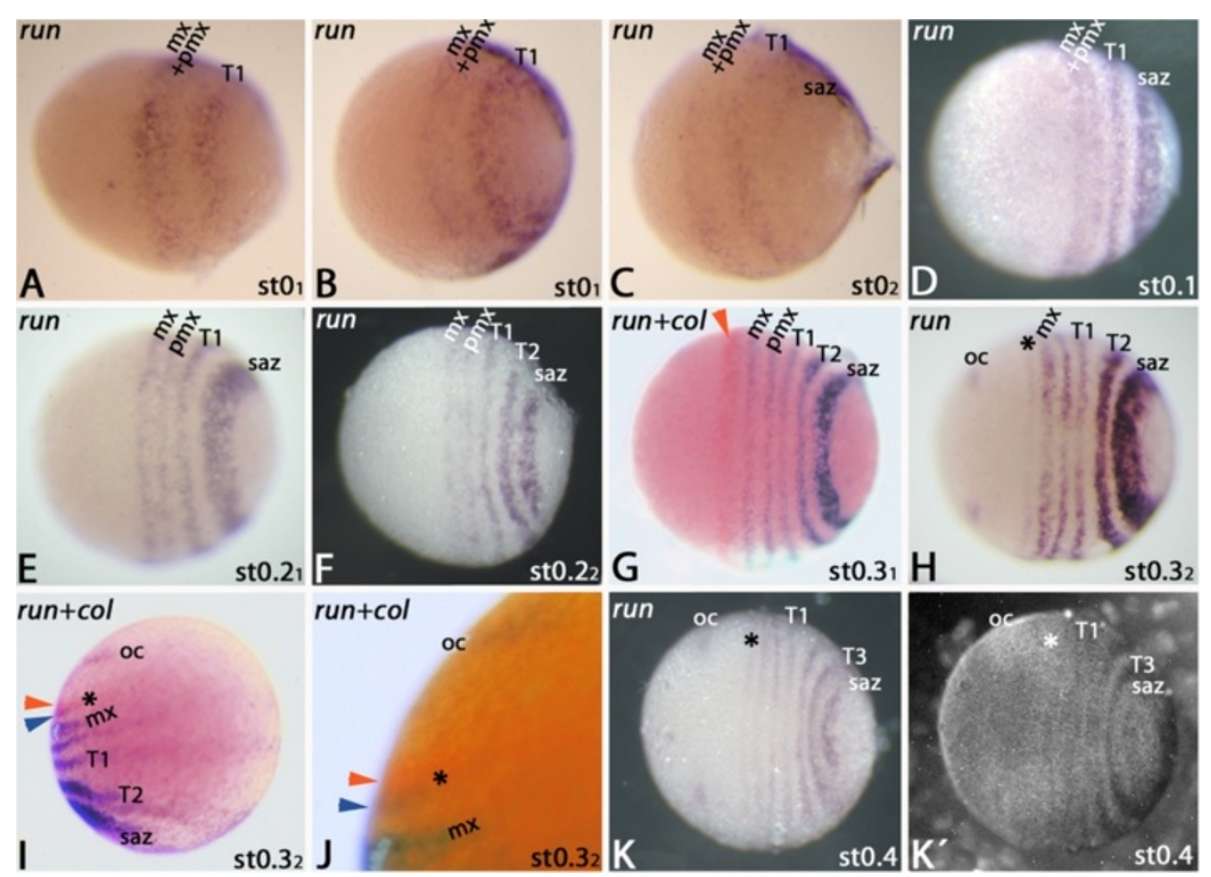

Figure 3 Expression of run in the regio germinalis. All embryos are oriented with anterior to the left and represent ventral views, except panels $(I)$ and $(J)$ which represent lateral views. The run ortholog is expressed as two broad stripes in the early blastoderm stage $(\mathbf{A}, \mathbf{B})$, of which the posterior contributes to the first trunk segment (T1) (C). (D) Stage 0.1 embryo. The anterior broad stripe splits. (E) Early stage 0.2 embryo. (F) Late stage 0.2 embryo. (G) Early stage 0.3 embryo double-stained for run (blue signal) and col (orange signal; expression of col is marked with an orange arrowhead). (H) Late stage 0.3 embryo. Asterisk marks faint expression in the mandibular segment. Expression in the ocular segment (oc) appears. (I) Late stage 0.3 embryo double-stained for run (expression in the mandibular segment is marked with a blue arrowhead) and col (orange arrowhead). Asterisk as in (H). Lateral view. (J) Magnification of the embryo shown in (I). Arrowheads and asterisk as in (I). (K) Stage 0.4 embryo. Asterisk as in (I). (K') DAPI staining of the embryo shown in (K). Abbreviations as in Figure 1.

(Figure 4E). Slightly later ventral expression of the ocular domain disappears (Figure 4F). Co-expression of $h 1$ with col reveals that the enhanced expression of $h 1$ in the antennal to mandibular domain lies in the posterior of the mandibular and antennal segment, respectively (Figure 4F/G). In late stage 0.4 embryos expression disappears from the ventral region of the antennal segment (Figure $4 \mathrm{H}$ ). The $h 1$-stripes that correspond to the postmaxillary segment, the maxillary segment, T1 and T2 become broadened and expression at the posterior rim becomes enhanced (Figure 4H). DAPI counter-staining reveals the affiliation of the stripes to their corresponding segments (Figure $4 \mathrm{H}^{\prime}$ ). Co-expression in similarstage embryos stained for $h 1$ and en shows that the centre of the antennal to mandibular domain harbors the premandibular segment primordium (Figure 4I/J). The posterior rim of segmental $h 1$-expression likely corresponds with the posterior portion of the developing segments ( $=$ en expressing tissue (cf. [11])). Enhanced dot-like expression of $h 1$ appears along the ventral edge of the embryo where the central nervous system forms (Figure 4K).

Expression of the second Glomeris hairy ortholog, $h 2$, appears in transversal stripes at stage 0.1 in the mandibular, maxillary and T1 segments and weakly in the SAZ (Figure 4L). Later, expression in the postmaxillary segment appears. Expression in the mandibular and the maxillary segment broadens and expression corresponding to the T3 stripe forms in the anterior SAZ (Figure $4 \mathrm{~N}$ ). Double staining shows that $h 2$ is expressed anterior and adjacent to the segment polarity gene engrailed (en) (Figure $4 \mathrm{O}$ and Additional file 1: Figure S1B).

\section{Expression of sloppy-paired (s/p) in the regio germinalis}

In the fly Drosophila and the beetle Tribolium slp acts as a secondary PRG and is in these species regulated by the primary PRGs [20]. In Drosophila it acts as a gap gene in the head segments and a pair rule like regulator of SPGs in the trunk segments where it functions as an activator of wingless $(w g)$ and as a repressor of engrailed (en) $[8,49]$.

At the Glomeris blastoderm stage, slp is expressed as a broad domain in the future premandibular+mandibular region (Figure 5A). A stripe of $s l p$ appears anterior to the SAZ and corresponds to the future T1 (Figure 5B). A new domain appears in the SAZ (Figure 5C). Then de novo expression appears in the ocular region and faintly 

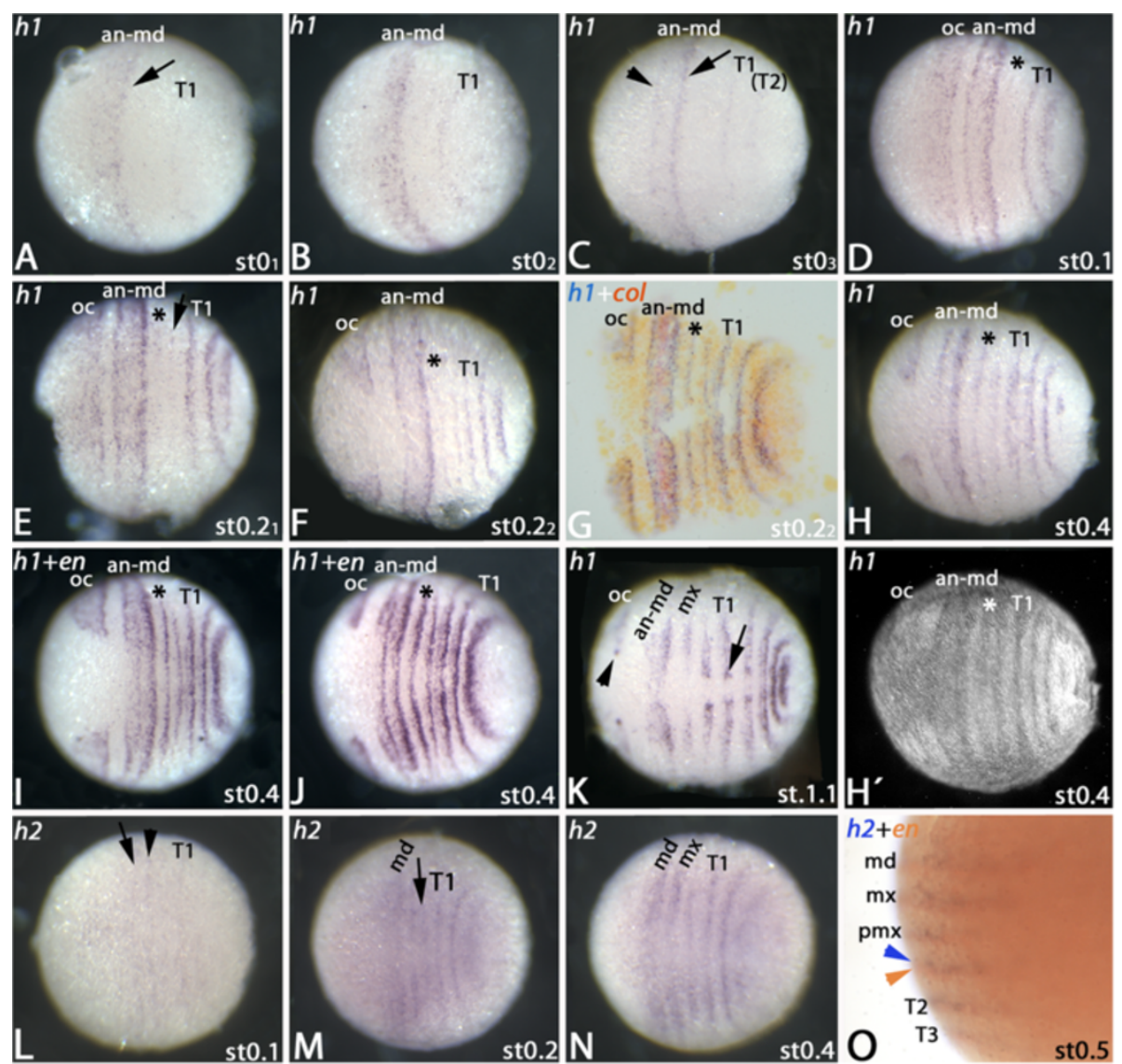

Figure 4 Expression of $\boldsymbol{h} \mathbf{1}$ in the regio germinalis. All embryos are oriented with anterior to the left and represent ventral views, except panel (O), which represents a lateral view. (A) Early blastoderm stage embryo. Arrow points to enhanced expression at the posterior rim of the anterior expression domain. (B) Slightly older embryo as the one shown in (A). (C) Late blastoderm stage embryo. Arrow as in (A). Arrowhead points to enhanced expression at the anterior rim of the broad anterior expression domain. (D) Stage 0.1 embryo. A second broad expression domain covering the ocular region appears. The asterisk marks very faint expression in the maxillary segment. (E) Early stage 0.2 embryo. Asterisk as in (D). The arrow marks faint expression in the postmaxillary segment. (F) Late stage 0.2 embryo. The ocular domain of $h 1$-expression has split. Asterisk as in (D). (G) Late stage 0.2 embryo double-stained for $h 1$ (blue signal) and col (orange signal). Asterisk as in (D). (H) Stage 0.4 embryo. Asterisk as in (D). ( $\left.\mathbf{H}^{\prime}\right)$ DAPI staining of the same embryo shown in (H). (I/J) Stage 0.4 embryos double-stained for $h 1$ and en (both detected as blue signals). Note that a stripe of en-expression lies in the broad domain of $h 1$-expression covering antennal to mandibular segments. Asterisks as in (D). (K) Stage 1.1 stained for $h 1$. Arrowhead and arrow point to enhanced expression in the developing neuroectoderm. (L) Expression of $h 2$ in a stage 0.1 embryo. Note that $h 2$ is not expressed at the blastoderm stage. Arrow and arrowhead mark faint expression in the mandibular and maxillary segment respectively. (M) Stage 0.2 embryo stained for $h 2$. Arrow points to upcoming expression in the postmaxillary segment. (N) Expression of $h 2$ in a stage 0.4 embryo. (0) Co-expression of h2 (blue signal) and en (orange signal). h2 (blue arrowhead) is expressed anterior and adjacent to en (orange arrowhead). Abbreviations as in Figure 1.

in the future maxillary segment (Figure 5D). Ventral expression of the former ocular stripe disappears. Expression appears in the SAZ corresponding to the future T3 segment (Figure 5E). Expression in the centre of the premandibular+mandibular domain starts disappearing and faint expression forms in the antennal region and the future postmaxillary segment (Figure 5F). Expression in the antennal and postmaxillary segment becomes stronger. Disappearing of $s l p$-transcripts from the premandibular+mandibular region proceeds (Figure 5G). At stage 1.2 these stripes are completely split into two. Double staining with engrailed (en) reveals that the segmental expression of slp is anterior and adjacent to en (Additional file Figure 1: S1C). The intrasegmental expression of $s l p$ is thus conserved in segments formed from the regio germinalis and the segment addition zone (cf. [24]). It appears thus possible that the function of slp as a regulator of the segment polarity genes $w g$ and en may indeed be conserved in both, insects and myriapods.

\section{Expression of pairberry-1 (pby-1) in the regio germinalis} In Drosophila the paired ( $p r d$ ) gene is classified as a socalled tertiary PRG because it functions at the lowest 


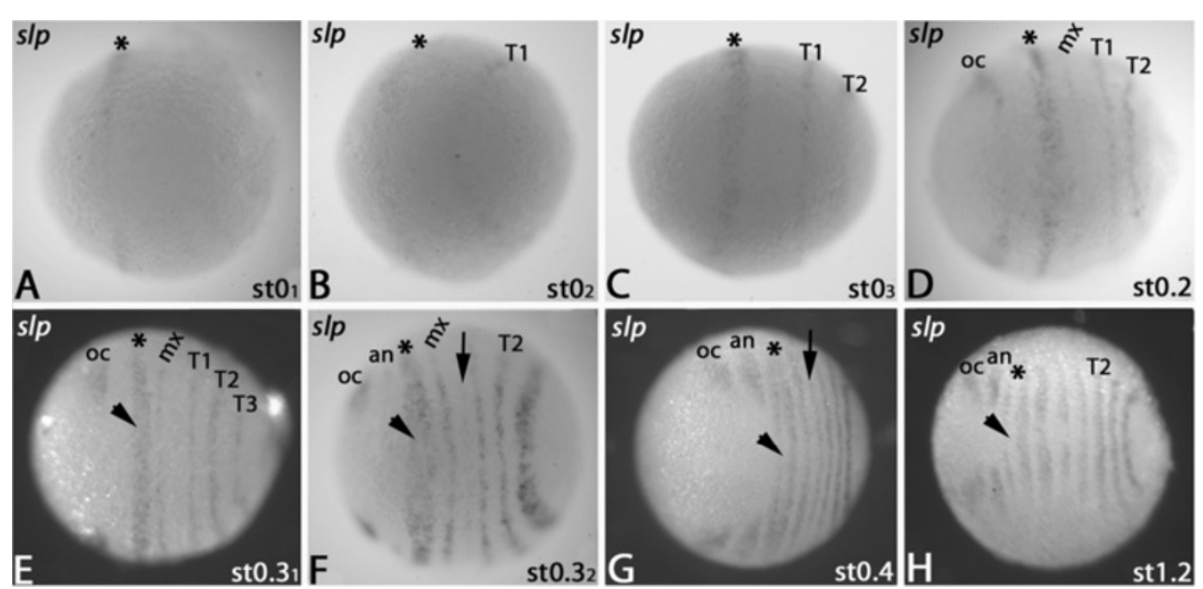

Figure 5 Expression of $s / p$ in the regio germinalis. All embryos are oriented with anterior to the left and represent ventral views. In all panels the asterisks mark progression of the early anterior expression domain. (A-C) Blastoderm stage embryos of subsequent stages. (D) Stage 0.2 embryo. (E) Stage 0.3 embryo. Arrowhead points to central region of the stripe covering premandibular+mandibular segments. (F) Later stage 0.3 embryo. The premandibular+mandibular stripe (asterisk) splits; transcripts in the centre of this domain disappear. The arrow points to faint expression in the postmaxillary segment. Arrowhead as in (E). (G) Stage 0.4 embryo. Arrow and arrowhead as in (E). (H) Stage 1.2 embryo. Arrowhead as in (E). Abbreviations as in Figure 1.

level of the pair rule gene cascade as a direct activator of wingless (wg) and engrailed (en) [50]. Expression and functional analysis of paired orthologs in other insects revealed that its function is conserved among insects (e.g. $[51,52])$.
The orthologs of the Drosophila pax group III genes are called pairberry-genes because they in fact represent the orthologs of the three Drosophila genes paired, gooseberry and gooseberry-neuro [53]. At stage 0.1 embryos, Glomeris pby-1 is expressed as a fuzzy domain
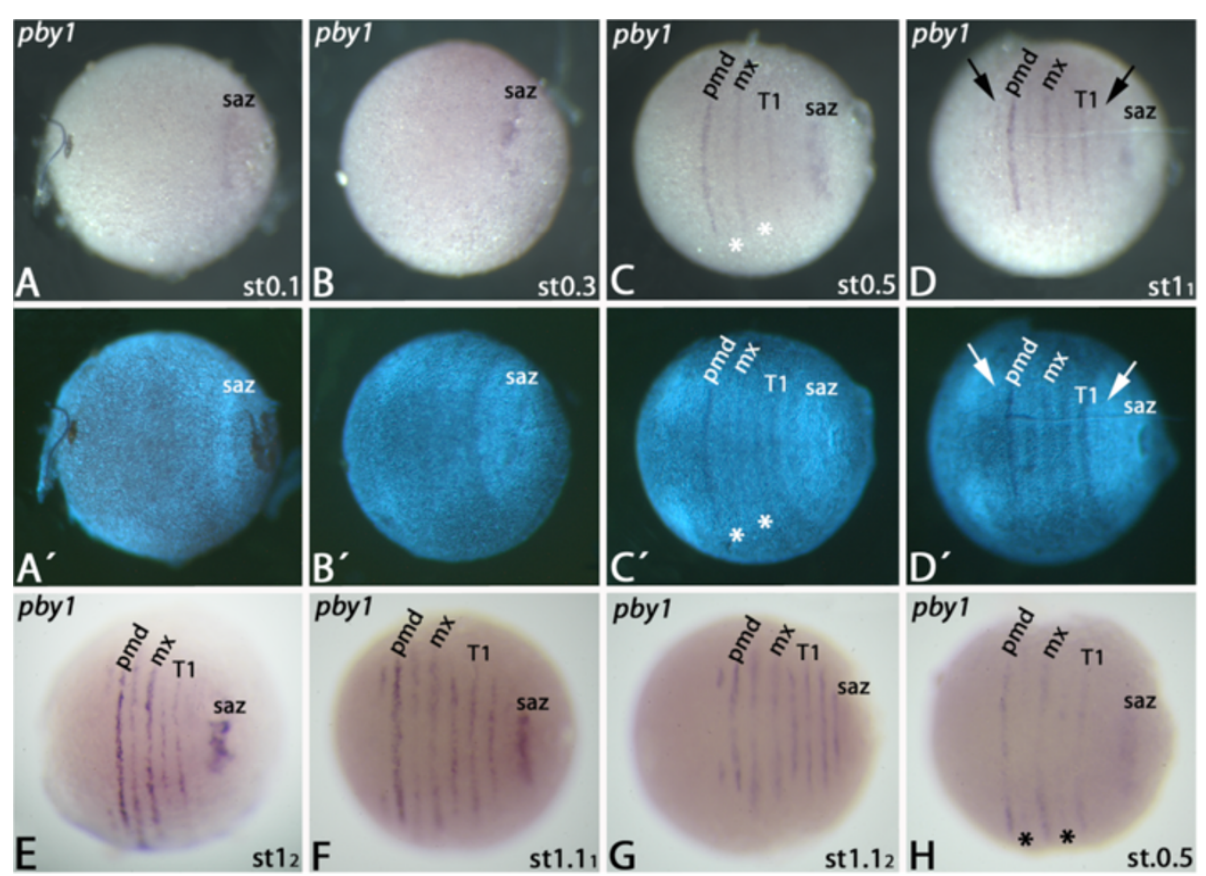

Figure 6 Expression of pby-1 in the regio germinalis. All embryos are oriented with anterior to the left and represent ventral views. (A) Stage 0.1 embryo. (B) Stage 0.3 embryo. (C) Stage 0.5 embryo. Segmental expression in the regio germinalis appears. (D) Early stage 1 embryo. Left arrow marks faint expression of pby-1 in the antennal segment; right arrow marks faint expression in the second trunk segment (T2). (E) Late stage 1 embryo. (F) Early stage 1.1 embryo. (G) Late stage 1.1 embryo. (H) Stage 0.5 embryo (cf. also (C)). Critical stage in which pby-1 is prominently transcribed in every other segment in the regio germinalis. Asterisks mark upcoming expression in the mandibular and postmaxillary segment. (A') to (D') DAPI counter-staining of the embryos shown in (A) to (D). Abbreviations as in Figure 1. 
within or directly anterior to the SAZ (Figure 6A/A'). This remains the only expression until stage 0.4 (Figure 6B/B' and not shown). Segmental expression appears simultaneously in the premandibular, the mandibular, the maxillary, postmaxillary and the T1 segment. Expression in the premandibular, the maxillary and the T1 segment, is clearly stronger (Figure 6C, H). During stage 0.5, faint expression appears in the antennal segment and in T2. At stage 1, expression in the mandibular and the postmaxillary segment becomes stronger (Figure 6D/E). During stage 1.1, the T3-stripe first appears as a faint expression (Figure 6F) that subsequently becomes clearer (Figure 6G).

Double staining with engrailed (en) reveals that pby-1 is expressed anterior to en in anterior segments that have formed from the regio germinalis (Additional file 1: Figure S1D). Both genes also appear to be co-expressed in one row of cells, but this is not unambiguously clear from the available expression data (Additional file 1: Figure S1D). The intrasegmental expression of $p b y-1$ is conserved in anterior and posterior segments (cf. [24]), and this is consistent with a conserved regulatory function of $p b y-1$ in segment polarity gene regulation.

\section{Expression of odd-paired (opa) and odd-skipped (odd) in} the regio germinalis

In Drosophila opa acts as a secondary PRG. An oddity of opa is that it is not expressed in the typical striped pattern as all the other PRGs, but it is expressed ubiquitously in the centre of the early embryo. Its presence is required but not instructive for the regulation of segment polarity genes $[7,54]$. In Tribolium opa is expessed in stripes but does not act as a pair rule gene [20].

At the blastoderm stage opa is ubiquitously expressed in the regio germinalis, but not in the SAZ (Figure 7A). Within this domain, expression is enhanced in the future premandibular+mandibular, maxillary+postmaxillary, and the T1 segment (Figure 7A). Later, the broad stripes corresponding to the premandibular+mandibular and maxillary+postmaxillary regions split. At the same time, the ubiquitous expression anterior to the premandibular segment transforms into distinct domains in the later ocular and antennal regions (Figure 7B). The T1domain does not split. De novo expression corresponding to T2 appears in the SAZ (Figure 7B). Later, the T3 stripe appears in the SAZ (Figure 7C). The expression of Glomeris opa in a striped pattern of enhanced expression within a ubiquitous domain is thus intermediate between that of Tribolium (in stripes) and that of Drosophila (fully ubiquitous).

Interestingly, in Drosophila the odd gene is historically considered as a secondary PRG that is under control of the primary PRGs, and is repressed by eve [41]. In Tribolium, however, odd is part of the high-level regulatory circuit that controls secondary PRGs, and even represses eve [20]. Based on the find that odd expression is regulated through stripe specific elements, recently it has

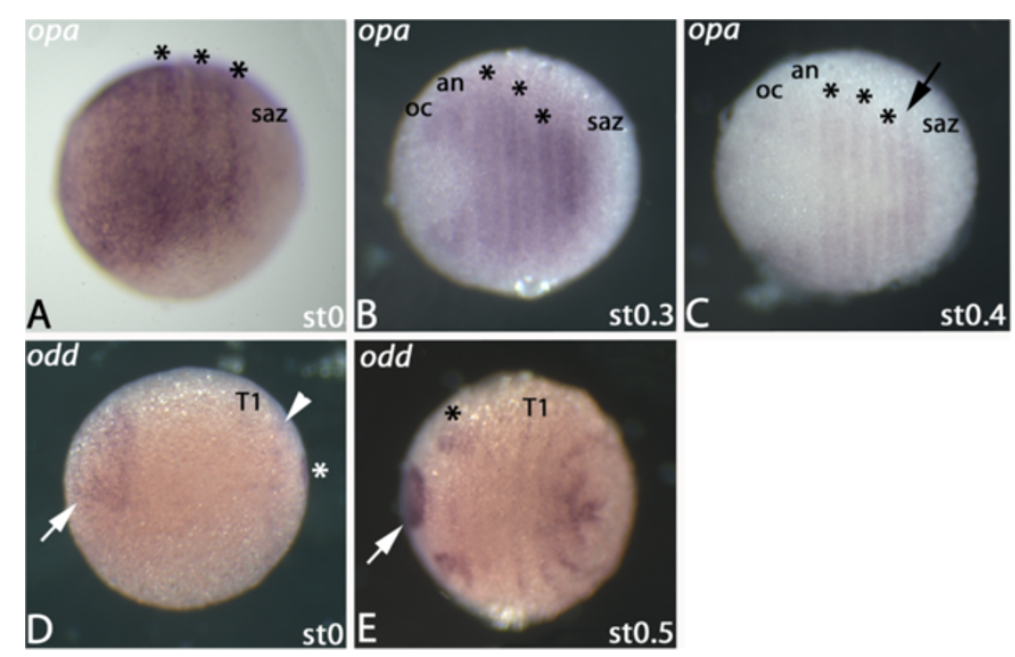

Figure 7 Expression of opa and odd in the regio germinalis. All embryos are oriented with anterior to the left and represent ventral views. (A) Expression of opa in a blastoderm stage embryo. Asterisks mark stripes of enhanced expression within a field of ubiquitous expression. (B) Expression of opa in a stage 0.3 embryo. Asterisks as in (A). Additional stripes of segmental expression form. (C) Stage 0.4 embryo expressing opa. Asterisks as in (A). The arrow points to expression in T2. (D) Expression of odd in a blastoderm stage embryo. Arrow points to expression at the very anterior of the embryo. Arrowhead points to weak expression anterior to the SAZ. Asterisk marks expression at the posterior pole of the embryo. (E) Stage 0.5 embryo stained for odd expression. Arrow as in (D). Asterisk marks dorsal expression within the gnathal segments. Abbreviations as in Figure 1. 
been suggested that Drosophila odd should rather be considered as a primary than a secondary PRG [46]. Furthermore also expression pattern analysis in another myriapod, the centipede Strigamia, suggests an important role for an odd-related gene in this species [55].

In Glomeris the odd gene is initially expressed in the most anterior area of the developing embryo, while being weakly expressed in the future T1, the SAZ and its posterior pole (Figure 7D). At stage 0.5 the anterior domain is restricted to a central position. Two patches of expression are located dorsal and posterior to this domain. The affiliation of this expression is unclear, but is possibly within future antennal, premandibular and mandibular tissue (Figure 7E). Faint expression is visible in developing segments between this domain and $\mathrm{T} 1$. Three stripes of expression appear posterior to T1 representing expression in the future segments $\mathrm{T} 2$ to $\mathrm{T} 4$ (Figure 7E). Altogether, the expression pattern of odd is not indicative for a pronounced role during the formation/patterning of segments that form from the regio germinalis. This implies that it does not play such a crucial role in the segmentation process in this myriapod as it does in long and short germ insects and a centipede. In segments that arise from the posterior segment addition zone (SAZ), however, Glomeris odd is prominently expressed in the SAZ itself and subsequently also in the dorsal segmental units [24]. This on the other hand suggests fundamental differences between the patterning of anterior vs posterior segments.
Other PRG orthologs, i.e. the paralogs pairberry-2 (pby2) and hairy-3 (h3) are not expressed in early stages in the regio germinalis.

\section{Discussion}

The Glomeris pby-1 gene is expressed in a pattern reminiscent of that of classical PRGs

An important question that must be addressed is whether PRG orthologs may be involved in a pair rulelike mechanism during segment formation and if this is comparable to that found in the model organism, Drosophila (e.g.[2,18]).

One of the investigated PRG orthologs in Glomeris, pby-1, is expressed in an early pattern in the regio germinalis and may be the result of an underlying classical pair rule-like mechanism. It appears simultaneously (or with very little delay) in the premandibular to T1 segment, but expression in every other segment, i.e. premandibular, maxillary and $\mathrm{T} 1$, is notably stronger (Figures 6 and 8). This expression profile is reminiscent of PRG expression in Drosophila, where an alternating pattern of weaker and stronger prd-stripes occurs after the splitting off of secondary stripes from primary stripes [56]. In Glomeris pby-1-stripes are, however, not the result of splitting. Notably, also in Glomeris, segmental expression of pby-1 appears significantly later than that of the other PRGs, and even later than the segmentpolarity gene en [11]. This late appearance of $p b y-1$ is in accord with its late appearance during posterior segment addition in Glomeris [24] and the confirmed role of prd as a tertiary PRG in Drosophila [50]. Therefore, pby-1

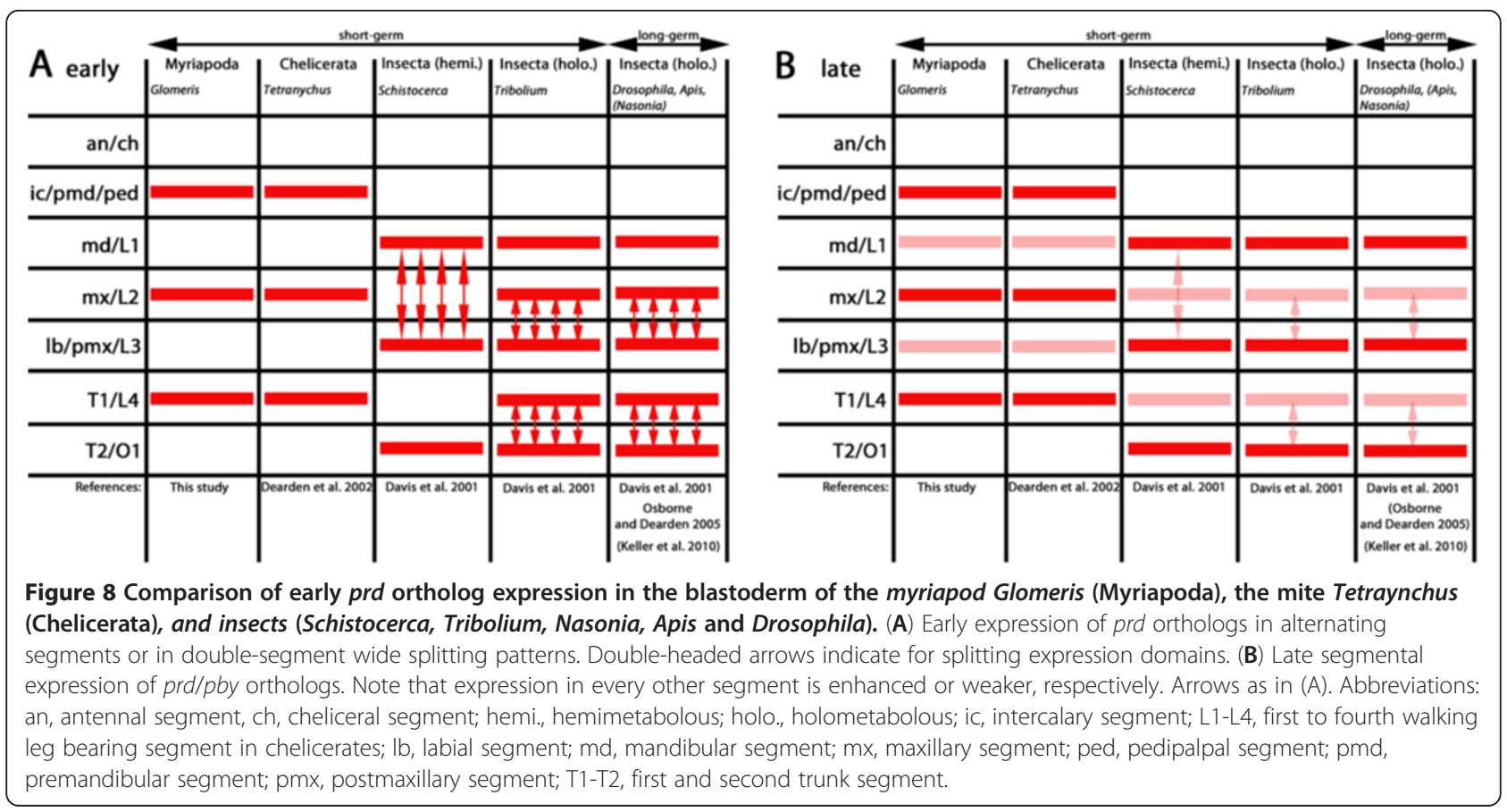


cannot act at high levels in the segmentation gene cascade in Glomeris, and is unlikely to be involved in the regulation of the SPGs. The expression pattern of $p b y-1$ can however be interpreted as a possible secondary result of an underlying primary pair rule-like mechanism.

The early expression of $p r d / p b y$ orthologs has also been examined in other insect species than Drosophila. In the wasp, Nasonia vitripennis, a long-germ insect, like Drosophila, stripes of prd expression appear in an anterior to posterior progression with every other stripe being weaker. Whether this is a result of splitting stripes like in Drosophila is unclear from the present data [57]. In the short-germ insect, Tribolium, broad stripes of prd expression appear that soon after split [53]. Notably, the maxillary stripe is weaker than the mandibular and labial stripes. With the elongation of the germ band, additional stripes of prd expression appear in the anterior of the $\mathrm{SAZ}$ that later split into expression in $\mathrm{T} 1+\mathrm{T} 2, \mathrm{~T} 3+\mathrm{A} 1$ et cetera. Importantly, in Tribolium, prd acts as a true PRG with a clear pair rule phenotype setting an example that splitting domains of double-segment wide initial expression patterns can be functionally comparable to Drosophila pair rule patterning [20,51]. In the hemimetabolous short-germ insect, Schistocerca americana, the mandibular and labial stripes of prd expression first appear together with a broad posterior domain that gives rise to expression in the second and third thoracic segment. With some delay weaker stripes in between (in the maxillary and the first thoracic segment) appear $[3,53]$. Notably, the mandibular stripe does not appear as a separate stripe but is the result of a broad splitting domain covering the gnathal arc that transforms also into the labial stripe [53].

The early pattern in long-germ and short-germ insects is therefore similar. Stripes form as broad doublesegment wide domains that then split giving rise to the secondary pattern of prd expression (Figure 8). The result is often a secondary expression pattern with strong and weak prd/pby expression in alternating segments (Figure 8), which is the pattern also present in Glomeris.

Interestingly, the same early expression profile of prd orthologs has also been described for the spider mite, Tetraynchus urticae (Chelicerata), where the paired ortholog, $T u-p a x 3 / 7$, is initially expressed in alternating segments in the anterior body. In somewhat later stages, expression of $T u-p a x 3 / 7$ appears in the interjacent segments [30]. This pattern is virtually identical to that of Glomeris pby-1 except the expression patterns of the first and third walking leg bearing segments (= mandibular and postmaxillary segments in Glomeris) in the mite are clearly delayed (Figure 8). This finding, if not caused by convergence, may place the origin of the expression pattern of prd orthologs (and possibly also its early function) at the very base of the Arthropoda.
The early strong expression of $T u$-pax3/7 is in the same (homologous) segments as the strong expression in Glomeris, but the location of the primary (stronger) prd/pby-stripes in insects is shifted by one segment towards posterior (Figure 8). Since the homology of arthropod head segments appears to be solidly resolved by brain innervation patterns (e.g. $[58,59])$ and Hox gene expression patterns (e.g. $[17,32,60,61])$, this difference must be the result of different regulation of $\mathrm{prd} / \mathrm{pby}$ genes in the different arthropod classes.

\section{Expression of PRGs in double-segment wide domains: a feature of pair rule function?}

We find that in Glomeris all PRGs except pby-1 are initially expressed in double- or multiple-segment wide domains in at least some segmental primordia (Figure 9). Most of the broad expression patterns in Glomeris extend into two adjacent future segments (Figure 9). Splitting of double-segment wide expression domains of PRGs is found also for one of the Drosophila PRGs, namely paired (prd) [53], and for a number of PRGs in other insects (e.g. [23,52,53]) (Figure 8) (discussed above). Functional studies in the beetle, Tribolium, have shown that this kind of expression pattern is indeed connected to classical pair rule phenotypes [19], but [20].

It is possible that the splitting of double-segment wide expression domains is an ancestral regulatory feature of arthropod PRGs, because it is present in the blastoderm of insects, a myriapod (this study) and also a spider [31].

Initial expression of PRGs in broad domains may be a genetic constraint, because their early expression patterns are likely to be regulated by the gap-genes (GGs), as known from insects (e.g. [23,62-65]). Since the GGs are expressed in broad domains they may activate PRGs that are also initially located in broad domains, but that then transform into segmental stripes, possibly by the combinatorial action of the PRGs themselves.

\section{Blastoderm patterning in long- and short-germ arthropods}

In the model arthropod, Drosophila melanogaster, all segments are patterned at the blastoderm stage. This, however, represents a derived developmental mode, and hence the segmentation gene cascade known to act in Drosophila cannot function in the same way in shortgerm arthropods that add posterior segments sequentially from a posterior SAZ (e.g. [66]).

Functional studies and gene expression analysis have shown that the PRGs are likely to be involved in segment formation in non-insect arthropods (e.g. $[24-26,55,67,68])$. Despite that, it was largely unclear whether PRGs are also involved in anterior patterning in non-insect arthropods, as only very few studies examine 


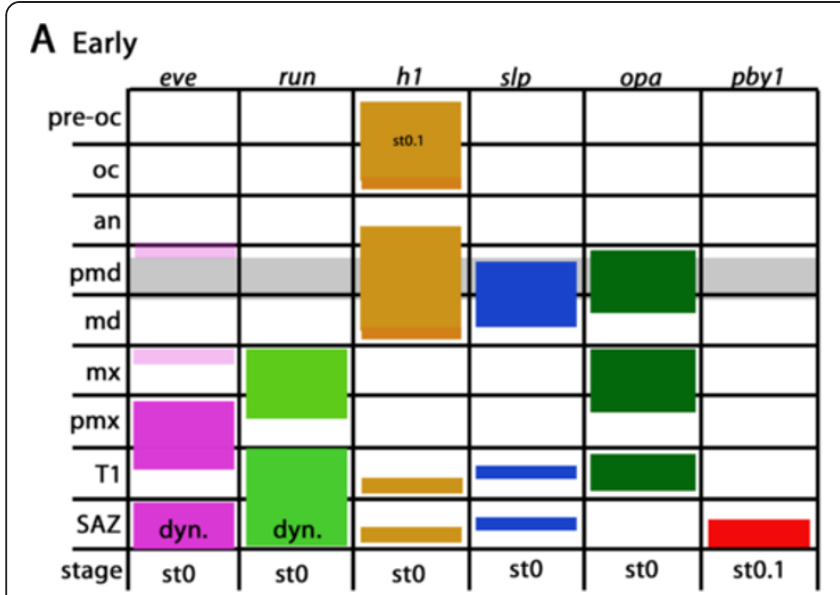

B Late

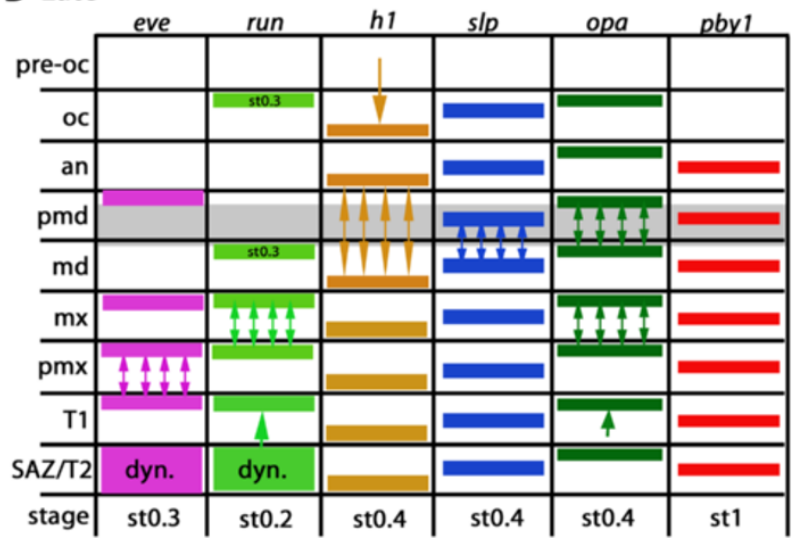

Figure 9 Schematic summary of PRG expression in the Glomeris blastoderm. (A) Early expression at the blastoderm stage. Note that the most anterior expression domain of $h 1$ and the expression of $p b y-1$ in the SAZ appear slightly later at stage 0.1. (B) Segmental expression at later stages. Double-headed arrows indicate splitting of initial double- (or triple-) segment wide expression domains into segmental stripes.

Single-headed arrows indicate refinement of broad expression domains into a single segmental stripe of expression. Abbreviations: an, antennal segment; dyn., dynamic expression; eve, even-skipped; h1, hairy-1; md, mandibular segment; mx, maxillary segment; oc, ocular field; opa, odd-paired; pby-1, pairberry-1; pmd, premandibular segment; pmx, postmaxillary segment; pre-oc, pre-ocular region; run, runt; SAZ, segment addition zone; slp, sloppy paired; st, stage; T1-T2, first and second trunk segment. The grey bar indicates expression of the molecular landmark collier.

PRG function and/or expression at early blastoderm stages in non-insect arthropods [30,31].

The data presented here suggest that most of the investigated PRGs in Glomeris are involved in segmental patterning of the blastoderm. All PRGs (except oddskipped) are expressed in transversal stripes corresponding to one or multiple segment primordia (discussed above). Expression of any given PRG does not appear simultaneously or in an anterior posterior order, but with minimal temporal variance in different segmental primordia. Furthermore, the order of appearance of the segmental primordia differs for every PRG ortholog (Figure 9). This is comparable to what happens in Drosophila, where the PRGs often appear in an irregular progression in the blastoderm and the initial expression is often in broad domains and not in the classical sevenstripe pattern (e.g. [54,56,69]).

The stereotypic appearance of the PRGs in the regio germinalis in Glomeris is superficially reflected by the appearance of the SPG en [11]. en transcription starts later compared to when most of the PRGs are transcribed, which is in accord with a possible regulatory function of some of the PRGs on en in the anterior embryo in Glomeris. While the PRGs appear to be active before the onset of the SPGs [11] and the expression of the Hox genes [32], the anterior acting GGs are expressed as early as, or possibly earlier [70].

The principal hierarchy of segmentation gene interaction known from Drosophila with GGs regulating PRGs and PRGs regulating SPGs can be conserved in Glomeris as well, at least with respect to segment formation in the blastoderm.
It is tempting to speculate that anterior patterning is indeed conserved among long- and short-germ arthropods and that this possibly ancestral patterning mechanism has been extended to the complete embryo in Drosophila and other long-germ insects. Results of this transition may have been the recruitment of the posterior acting GGs and the loss of the posterior segmentation clock as suggested by [71].

\section{Pair rule-like mechanism in posterior segment addition?}

Patterning of segments in pairs may be an ancestral mechanism (discussed above). The dynamic expression of some PRGs in the posterior SAZ in myriapods $[14,24,55,68]$ may be the equivalent of double-segment wide stripes of PRGs in the blastoderm. This condition is most evident in the centipede, Strigamia, where the addition of posterior segments occurs in pairs and with the involvement of PRGs, such as even-skipped, from the posterior SAZ [68]. Further evidence for this hypothesis comes from centipedes where the number of trunk segments is always odd (reviewed in $[72,73])$. This shows that there may be a genetic constraint that does not allow for the formation of an even number of trunk segments in centipedes [74].

Furthermore, in Glomeris the number of trunk segments is always 17 for females and 19 for males. This indicates that the posterior segmentation clock in Glomeris males may produce another two segments by adding one cycle of dynamic gene expression during its development.

\section{Conclusions}

We have found evidence, in the form of gene expression patterns, that Drosophila pair rule gene orthologs are 
also likely involved in anterior body patterning in the myriapod Glomeris marginata. This finding, however, requires further investigation through functional studies, which, at the moment, have not yet been established for Glomeris, or any other myriapod species. The expression patterns found in Glomeris are, to some extent, similar, and thus reminiscent of true pair rule patterning as seen in Drosophila. Comprehensive comparative expression data from other arthropods, and especially crustaceans, are necessary to gain a better understanding of the ancestral mode(s) of arthropod segmentation.

\section{Addittional file}

Additional file 1: Figure S1. Intrasegmental expression of PRGS revealed by double-staining with the SPG engrailed (en). In all panels anterior is to the left. A Stage 1.2 embryo, flat-mounted. Double staining of en (orange signal) and even-skipped (eve, blue signal). B Stage 0.5 embryo, whole mount. Double staining of en (orange signal) with hairy-2 ( $h 2$, blue signal). C Stage 0.5 embryo, flat-mounted. Double staining of en (orange signal) and sloppy-paired (blue signal). Note that the anterior of the germ band was damaged during the process of mounting and removing the yolk. D Stage 1.1 embryo, flat-mounted. Double staining of en (orange signal) and pairberry-1 (blue signal). Abbreviations: an, antennal segment; md, mandibular segment; pmd, premandibular segment; pmx, postmaxillary segment; $\mathrm{T} 1$ and $\mathrm{T} 3$, first and third trunk segment.

\section{Authors' contributions}

RJ designed the study, conducted the experiments and wrote the first draft manuscript. WGMD and GEB were involved in data discussion and writing the final version of the manuscript. All authors approved the final version of the manuscript.

\section{Acknowledgements}

This work has been supported by the Swedish Research Council (VR: grant to GEB), the European Union via the Marie Curie Training network "ZOONET" (MRTN-CT-2004-005624 (to GEB, WGMD and RJ)) and the DFG via SFB 572 of the University of Cologne (to WGMD and RJ).

\section{Author details}

'Department of Earth Sciences, Uppsala University, Villavägen 16, 75236 Uppsala, Sweden. ${ }^{2}$ Department of Genetics, Friedrich-Schiller-University Jena, Philosophenweg 12, 07743 Jena, Germany.

Received: 17 October 2011 Accepted: 11 April 2012

Published: 17 May 2012

\section{References}

1. Akam M: The molecular basis for metameric pattern in the Drosophila embryo. Development 1987, 101:1-22.

2. Pankratz MJ, Jäckle H: Blastoderm segmentation. In The development of Drosophila melanogaster. Edited by Bate M, Martinez Arias A. Cold Spring Harbor: Cold Spring Harbor Laboratory Press; 1993:467-516.

3. Davis GK, Patel NH: Playing by pair rules? BioEssays 2003, 25:425-429.

4. Fröhnhofer $\mathrm{HG}$, Nüsslein-Volhard C: Organization of anterior pattern in the Drosophila embryo by the maternal gene bicoid. Nature 1986, 324:120-125.

5. McGregor AP: How to get ahead: the origin, evolution and function of bicoid. BioEssays 2005, 27:904-913.

6. Jäckle H, Hoch M, Pankratz MJ, Gerwin N, Sauer F, Brönner G: Transcriptional control by Drosophila gap genes. J Cell Sci Supp/ 1992, 16:39-51.

7. Ingham PW, Baker NE, Martinez-Arias A: Regulation of segment polarity genes in the Drosophila blastoderm by fushi tarazu and even skipped. Nature 1988, 331:73-75.
8. Cadigan KM, Grossniklaus U, Gehring WJ: Localized expression of sloppy paired protein maintains the polarity of Drosophila parasegments. Genes Dev 1994, 8:899-913.

9. Sanson B: Generating patterns from fields of cells. EMBO reports 2001, 2:1083-1088.

10. Davis GK, Patel NH: Short, long and beyond: molecular and embryological approaches to insect segmentation. Annu Rev Entomol 2002, 47:669-699.

11. Janssen R, Prpic NM, Damen WG: Gene expression suggests decoupled dorsal and ventral segmentation in the millipede Glomeris marginata (Myriapoda: Diplopoda). Dev Biol 2004, 268:89-104.

12. Janssen R, Budd GE, Damen WG, Prpic NM: Evidence for Wg-independent tergite boundary formation in the millipede Glomeris marginata. Dev Genes Evol 2008, 218:361-370.

13. Damen WG: Parasegmental organization of the spider embryo implies that the parasegment is an evolutionary conserved entity in arthropod embryogenesis. Development 2002, 129:1239-1250.

14. Hughes $\mathrm{CL}$, Kaufman TC: Exploring myriapod segmentation: the expression patterns of even-skipped, engrailed, and wingless in a centipede. Dev Biol 2002, 247:47-61.

15. Hughes CL, Kaufman TC: Hox genes and the evolution of the arthropod body plan. Evol Dev 2002, 4:459-499.

16. Eriksson BJ, Tait NN, Budd GE, Akam M: The involvement of engrailed and wingless during segmentation in the onychophoran Euperipatoides kanangrensis (Peripatopsidae: Onychophora) (Reid 1996). Dev Genes Evol 2009, 219:249-264.

17. Eriksson BJ, Tait NN, Budd GE, Janssen R, Akam M: Head patterning and Hox gene expression in an onychophoran and its implications for the arthropod head problem. Dev Genes Evol 2010, 220:117-122.

18. Damen WG: Evolutionary conservation and divergence of the segmentation process in arthropods. Dev Dyn 2007, 236:1379-1391.

19. Aranda M, Marques-Souza H, Bayer T, Tautz D: The role of the segmentation gene hairy in Tribolium. Dev Genes Evol 2008, 218:465-477.

20. Choe CP, Miller SC, Brown SJ: A pair rule gene circuit defines segments sequentially in the short-germ insect Tribolium castaneum. Proc Natl Acad Sci USA 2006, 103:6560-6564.

21. Erezyilmaz DF, Kestrup HC, Riddiford LM: The nuclear receptor E75E has a novel pair-rule-like function in patterning the milkweed bug, Oncopeltus fasciatus. Dev Biol 2009, 334:300-310.

22. Binner $P$, Sander $K$ : Pair-rule patterning in the honeybee Apis mellifera: Expression of even-skipped combines traits known from beetles and fruitfly. Dev Genes Evol 1997, 206:447-454.

23. Wilson MJ, Havler M, Dearden PK: Giant, Krüppel, and caudal act as gap genes with extensive roles in patterning the honeybee embryo. Dev Biol 2010, 339:200-211.

24. Janssen R, Budd GE, Prpic NM, Damen WG: Expression of myriapod pair rule gene orthologs. Evodevo 2011, 2:5.

25. Damen WG, Janssen R, Prpic NM: Pair rule gene orthologs in spider segmentation. Evol Dev 2005, 7:618-628.

26. Schoppmeier M, Damen WG: Expression of Pax group III genes suggests a single-segmental periodicity for opisthosomal segment patterning in the spider Cupiennius salei. Evol Dev 2005, 7:160-167.

27. Brown SJ, Parrish JK, Beeman RW, Denell RE: Molecular characterization and embryonic expression of the even-skipped ortholog of Tribolium castaneum. Mech Dev 1997, 61:165-173.

28. Mito T, Kobayashi C, Sarshima I, Hongjie Z, Shinahara W, Miyawaki K, Shinmyo Y, Ohuchi H, Noji S: Even-skipped has gap-like, pair-rule-like, and segmental functions in the cricket Gryllus bimaculatus, a basal, intermediate germ insect (Orthoptera). Dev Biol 2007, 303:202-213.

29. Peel A: The evolution of arthropod segmentation mechanisms. BioEssays 2004, 26:1108-1111.

30. Dearden PK, Donly C, Grbic M: Expression of pair rule gene homologues: early patterning of the two-spotted spider mite Tetranychus urticae. Development 2002, 129:5461-5472.

31. Pechmann M, McGregor AP, Schwager EE, Feitosa NM, Damen WG: Dynamic gene expression is required for anterior regionalization in a spider. Proc Natl Acad Sci USA 2009, 106:1468-1472.

32. Janssen R, Damen WG: The ten Hox genes of the millipede Glomeris marginata. Dev Genes Evol 2006, 216:451-465.

33. Telford MJ: Evidence for the derivation of the Drosophila fushi tarazu gene from a Hox gene orthologous to lophotrochozoan Lox5. Curr Biol 2000, 10:349-352. 
34. Damen WG: Fushi tarazu: a Hox gene changes its role. Bioessays 2002, 24:992-995.

35. Prpic NM, Tautz D: The expression of the proximodistal axis patterning genes Distal-less and dachshund in the appendages of Glomeris marginata (Myriapoda: Diplopoda) suggests a special role of these genes in patterning the head appendages. Dev Biol 2003, 260:97-112.

36. Dohle W: Die Embryonalentwicklung von Glomeris marginata (Villers) im Vergleich zur Entwicklung anderer Diplopoden. Zool Jahrb Anat 1964, 81:241-310

37. Janssen R, Le Gouar M, Pechmann M, Poulin F, Bolognesi R, Schwager EE, Hopfen C, Colbourne JK, Budd GE, Brown SJ, Prpic NM, Kosiol C, Damen WG, Balavoine G, McGregor AP: Conservation, loss, and redeployment of Wnt ligands in protostomes: implications for understanding the evolution of axis elongation and segmentation. BMC Evol Biol 2010, 10:374.

38. Goto T, Macdonald P, Maniatis T: Early and late periodic patterns of even skipped expression are controlled by distinct regulatory elements that respond to different spatial cues. Cell 1989, 57:413-422

39. Small S, Blair A, Levine M: Regulation of even-skipped stripe 2 in the Drosophila embryo. EMBO J 1992, 11:4047-4057.

40. Small S, Arnosti DN, Levine M: Spacing ensures autonomous expression of different stripe enhancers in the even-skipped promoter. Development 1993, 119:762-772

41. Fujioka M, Jaynes JB, Goto T: Early even-skipped stripes act as morphogenetic gradients at the single cell level to establish engrailed expression. Development 1995, 121:4371-4382

42. Schroeder R, Jay DG, Tautz D: Elimination of EVE protein by CALI in the short germ band insect Tribolium suggests a conserved pair-rule function for even skipped. Mech Dev 1999, 80:191-195.

43. Liu PZ, Kaufman TC: even-skipped is not a pair-rule gene but has segmental and gap-like functions in Oncopeltus fasciatus, an intermediate germband insect. Development 2005, 132:2081-2092.

44. Janssen R: Diplosegmentation in the pill millipede Glomeris marginata is the result of dorsal fusion. Evol Dev 2011, 13:477-487.

45. Janssen R, Damen WG, Budd GE: Expression of collier in the premandibular segment of myriapods: support for the traditional Atelocerata concept or a case of convergence? BMC Evol Biol 2011, 11:50.

46. Schroeder MD, Greer C, Gaul U: How to make stripes: deciphering the transition from non-periodic to periodic patterns in Drosophila segmentation. Development 2011, 138:3067-3078.

47. Langeland JA, Carroll SB: Conservation of regulatory elements controlling hairy pair-rule stripe formation. Development 1993, 117:585-596.

48. Pueyo Jl, Lanfear R, Couso JP: Ancestral Notch-mediated segmentation revealed in the cockroach Periplaneta americana. Proc Natl Acad Sci USA 2008, 105:16614-16619.

49. Grossniklaus U, Cadigan KM, Gehring WJ: Three maternal coordinate systems cooperate in the patterning of the Drosophila head. Development 1994, 120:3155-3171.

50. Baumgartner $\mathrm{S}$, Noll M: Network of interactions among pair-rule genes regulating paired expression during primordial segmentation of Drosophila. Mech Dev 1990, 33:1-18.

51. Choe CP, Brown SJF: Evolutionary flexibility of pair rule patterning revealed by functional analysis of secondary pair rule genes, paired and sloppy-paired in the short-germ insect, Tribolium castaneum. Dev Biol 2007, 302:281-294.

52. Osborne PW, Dearden PK: Expression of Pax group III genes in the honeybee (Apis mellifera). Dev Genes Evol 2005, 215:499-508.

53. Davis GK, Jaramillo CA, Patel NH: Pax Group III genes and the evolution of insect pair rule patterning. Development 2001, 128:3445-3458.

54. Benedyk MJ, Mullen JR, DiNardo S: odd-paired: a zinc finger pair rule protein required for the timely activation of engrailed and wingless in Drosophila embryos. Genes Dev 1994, 8:105-117.

55. Chipman AD, Arthur W, Akam M: A double segment periodicity underlies segment generation in centipede development. Curr Biol 2004, 14:1250-1255

56. Gutjahr T, Frei E, Noll MF: Complex regulation of early paired expression: initial activation by gap genes and pattern modulation by pair rule genes. Development 1993, 117:609-623.

57. Keller RG, Desplan C, Rosenberg MI: Identification and characterization of Nasonia Pax genes. Ins Mol Biol 2010, 19:109-120.
58. Mittmann B, Scholtz G: Development of the nervous system in the "head" of Limulus polyphemus (Chelicerata: Xiphosura): morphological evidence for a correspondence between the segments of the chelicerae and of the (first) antennae of Mandibulata. Dev Genes Evol 2003, 213:9-17.

59. Harzsch S, Wildt M, Battelle B, Waloszek D: Immunohistochemical localization of neurotransmitters in the nervous system of larval Limulus polyphemus (Chelicerata, Xiphosura): evidence for a conserved protocerebral architecture in Euarthropoda. Arthropod Struct Dev 2005, 34:327-342

60. Telford MJ, Thomas RH: Expression of homeobox genes shows chelicerate arthropods retain their deuterocerebral segment. Proc Natl Acad Sci USA 1998, 95:10671-10675.

61. Damen WG, Hausdorf M, Seyfarth E-A, Tautz D: A conserved mode of head segmentation in arthropods revealed by the expression pattern of Hox genes in a spider. Proc Natl Acad Sci USA 1998, 95:10665-10670.

62. Goltsev $Y$, Hsiong W, Lanzaro G, Levine M: Different combinations of gap repressors for common stripes in Anopheles and Drosophila embryos. Dev Biol 2004, 275:435-446.

63. Eckert C, Aranda M, Wolff C, Tautz D: Separable stripe enhancer elements for the pair rule gene hairy in the beetle Tribolium. EMBO Rep 2004, 5:638-642.

64. Mito T, Okamoto H, Shinahara W, Shinmyo Y, Miyawaki K, Ohuchi H, Noji S: Krüppel acts as a gap gene regulating expression of hunchback and even-skipped in the intermediate germ cricket Gryllus bimaculatus. Dev Biol 2006, 294:471-481

65. García-Solache M, Jaeger J, Akam M: A systematic analysis of the gap gene system in the moth midge Clogmia albipunctata. Dev Biol 2010, 344:306-318.

66. Sander K: Specification of the basic body pattern in insect embryogenesis. Adv Insect Physiol 1976, 12:125-238.

67. Damen WG, Weller M, Tautz D: The expression patterns of hairy, evenskipped, and runt in the spider Cupiennius salei imply that these genes were segmentation genes in a basal arthropod. Proc Natl Acad Sci USA 2000, 97:4515-4519.

68. Chipman AD, Akam M: The segmentation cascade in the centipede Strigamia maritima: involvement of the Notch pathway and pair rule gene homologues. Dev Biol 2008, 319:160-169.

69. Macdonald PM, Ingham P, Struhl G: Isolation, structure, and expression of even-skipped: a second pair-rule gene of Drosophila containing a homeo box. Cell 1986, 47:721-734

70. Janssen R, Budd GE, Damen WG: Gene expression suggests conserved mechanisms patterning the heads of insects and myriapods. Dev Biol 2011, 357:64-72.

71. Peel A, Akam M: Evolution of segmentation: Rolling back the clock. Curr Biol 2003, 13:R708-R710.

72. Arthur W, Chipman AD: The centipede Strigamia maritima: what it can tell us about the development and evolution of segmentation. BioEssays 2005, 27:653-660.

73. Edgecombe GD, Giribet G: Evolutionary biology of centipedes (Myriapoda: Chilopoda). Annu Rev Entomol 2007, 52:151-170.

74. Arthur W, Farrow M: The pattern of variation in centipede segment number as an example of developmental constraint in evolution. $J$ Theor Biol 1999, 200:183-191.

doi:10.1186/1471-213X-12-15

Cite this article as: Janssen et al:: Expression of pair rule gene orthologs

in the blastoderm of a myriapod: evidence for pair rule-like mechanisms? BMC Developmental Biology 2012 12:15. 